\title{
Políticas públicas de educação ambiental e a atuação dos Conselhos de Meio Ambiente no Brasil: perspectivas e desafios
}

Victor Novicki *

Donaldo Bello de Souza**

\section{Resumo}

0 presente artigo visa à reflexão sobre a atuação dos Conselhos de Meio Ambiente (CMA) no campo da Educação Ambiental (EA), tomando por base teórico-conceitual, de um lado, as recomendações advindas de Conferências Internacionais, como Tbilisi e o Tratado de Educação Ambiental para Sociedades Sustentáveis e Responsabilidade Global (TEASS), e, de outro, a consideração dos marcos jurídicos que regulam as politicas públicas de gestão ambiental e de EA no Brasil, isto também levando em conta alguns resultados de pesquisas teóricoempíricas que tomam essas instâncias colegiadas por alvo de análise. Mesmo ponderando as contradições inerentes ao modo de produção capitalista e o autoritarismo que caracteriza o processo político brasileiro, conclui-se que os CMA podem vir a contribuir para a gestão dos problemas socioambientais e, a um só tempo, fortalecer a sociedade civil e o interesse público no interior do aparelho de Estado, especialmente pela via da EA.

Palavras-chave: Educação ambiental. Conselhos de meio ambiente. Participação social. Políticas públicas de meio ambiente. Conferências internacionais.

\section{Environmental education's public policies and the Environment Council Actions in Brazil: perspectives and challenges}

\section{Abstract}

This article aims to reflect on the actions of the Environment Council (EC) in the field of Environmental Education (EE), taking on for theoretical-conceptual

Doutor em Ciências Sociais, UNICAMP; Professor Adjunto e Pesquisador no Programa de Pós-Graduação em Educação, Universidade Católica de Petrópolis (UCP). E-mail: victor.novicki@globo.com

.. Doutor em Educação, UFRJ; Professor Adjunto da área de Economia da Educação, Depto de Políticas Públicas, Gestão e Avaliação da Educação da Faculdade de Educação, Universidade do Estado do Rio de Janeiro. E-mail: donaldosouza@hotmail.com 
basis, on the one hand, the recommendations arising from international conferences, such as Tbilisi and the Treaty of Environmental Education for Sustainable Societies and Global Responsibility, and another, the consideration of the legal frameworks governing the public policies of environmental management and EE in Brazil, this also taking into account some results of empirical-theoretical researches, which takes EC as target of analysis. Even considering the inherent contradictions of the capitalist mode of production and authoritarianism that characterizes the Brazilian political process, it was concluded that the EC may contribute to the management of socioenvironmental problems and, simultaneously, strengthen civil society and the public interest within the state apparatus, especially through the EE. Keywords: Environmental education. Council of environment. Social participation. Environment public policies. International conferences.

\section{Las politicas públicas de educación ambiental y la actuación de los Consejos de Medio Ambiente en Brasil: perspectivas $y$ desafios Resumen}

El presente artículo reflexiona sobre la actuación de los Consejos de Medio Ambiente (CMA) en el campo de la Educación Ambiental (EA), tomando por base teórico-conceptual, por un lado, las recomendaciones oriundas de Conferencias Internacionales, como Tbilisi y el Tratado de Educación Ambiental hacia Sociedades Sustentables y de Responsabilidad Global (TEASS) y, por otro, la consideración de los marcos jurídicos que regulan las políticas públicas de gestión ambiental y de EA en Brasil, sumados a algunos resultados de investigaciones teórico-empíricas que analizan esas instancias colegiadas. Sin dejar de observar las contradicciones inherentes al modo de producción capitalista y al autoritarismo que caracteriza el proceso político brasileño, se concluye que los CMA pueden contribuir para la gestión de los problemas socio ambientales $y$, paralelamente, fortalecer la sociedad civil y el interés público en el interior del aparato de Estado, especialmente por la vía de la EA.

Palabras clave: Educación ambiental. Consejos de medio ambiente. Participación social. Políticas públicas de medio ambiente. Conferencias internacionales.

\section{Introdução}

No chamado ecocapitalismo (HAWKEN; LOVINS; LOVINS, 1999), que se ancora nos limites externos à sustentabilidade - esgotamento e poluição da natureza/meio ambiente (FOLADORI, 2001) -, é possivel identificar-se duas propostas que, em sintese, defendem, de um lado, a correção de falha nos mecanismos de ajuste do mercado por intermédio da internalização da poluição no custo de produção e, de outro, a 
adoção de tecnologias limpas ou ditas ecoeficientes, pois levariam ao uso racional dos recursos naturais. Na abordagem ecocapitalista, o foco encontra-se posto no desenvolvimento sustentável, possivel de ser atingido pela via de um dito ambientalismo de livre mercado, pois presume que este consiste num instrumento eficiente para a alocação e consumo racional dos recursos planetários (DELUIZ; NOVICKI, 2004).

Sob uma perspectiva crítica (BURKET, 1999; LÖWY, 2005; ALTVATER, 1995, 1999), sem desconsiderar os avanços tecnológicos - que não são colocados a serviço de todos os seres humanos -, a sustentabilidade é entendida como o "processo pelo qual as sociedades administram as condições materiais de sua reprodução, redefinindo os princípios éticos e sociopolíticos que orientam a distribuição de seus recursos ambientais" (ACSELRAD; LEROY, 1999, p. 28). Tal concepção, fundada na equidade enquanto princípio das sociedades sustentáveis ${ }^{1}$, possui pressupostos que se ancoram na tradição marxista da crítica à economia política, ou seja, se voltam para o exame crítico das sociedades que se organizam em torno da propriedade privada dos meios de produção, da subsunção do trabalho ao capital e, por conseguinte, da lógica do processo de acumulação capitalista (MARX, 1988). Trata-se de um tipo de análise, portanto, que se pauta na crítica ao modelo de desenvolvimento capitalista e, consequentemente, nos pressupostos que norteiam a noção de sociedade sustentável, revelando-nos a necessidade de construção "de alternativas societárias democráticas que superem a desigualdade social e a degradação das próprias bases materiais do modo de produção" (DELUIZ; NOVICKI, 2004, p. 24).

Contudo, em ambas as visões de mundo a Educação Ambiental (EA) assume centralidade pois, visando a atender aos interesses em disputa, por seu intermédio, busca-se ocultar ou explicitar as causas da exclusão social e da questão ambiental, esta última entendida como conflito entre os interesses privados, que visam ao processo de acumulação capitalista, e o bem público, ou seja, o meio ambiente.

Um entre os vários espaços institucionais onde os interesses plurais em torno da questão ambiental podem ser captados consiste nos Conselhos de Meio Ambiente (CMA), órgão pertencente aos sistemas nacional, estaduais e municipais de meio ambiente que, no Brasil, começam a assumir importância na formulação das políticas nessa área especial-

\footnotetext{
Segundo Diegues (1992, p. 28): “0 conceito de 'sociedades sustentáveis' parece ser mais adequado que o de 'desenvolvimento sustentável' na medida em que possibilita a cada uma delas definir seus padrões de produção e consumo, bem como o de bem-estar a partir de sua cultura, de seu desenvolvimento histórico e de seu ambiente natural. Além disso, deixa-se de lado o padrão das sociedades industrializadas, enfatizando-se a possibilidade da existência de uma diversidade de sociedades sustentáveis, desde que pautadas pelos princípios básicos da sustentabilidade ecológica, econômica, social e política, anteriormente descritos. Essa noção de sociedades sustentáveis se baseia na noção expressa por Chambers na qual as pessoas, sobretudo as mais pobres, devem ser sujeitos e não objetos do 'desenvolvimento'. 0 meio ambiente e o desenvolvimento, para esse autor, são meios e não fins em si mesmos. Nesse sentido ele se refere à sustentabilidade dos modos de vida, (sustainable livelihoods) onde a qualidade de vida passa a ser uma prioridade.
} 
mente a partir da promulgação, em 1981, da Política Nacional de Meio Ambiente (PNMA) (BRASIL, 1981). Embora a EA se tenha configurado em uma das atribuições desses conseIhos, será somente em 1999 que se verificará a formulação de uma Política Nacional de Educação Ambiental (PNEA) (BRASIL, 1999) a qual, dado o seu caráter crítico, assumirá o trato político das questões ambientais e, em consequência, sublinhará a importância da participação social nesse processo, em que e pelo qual a EA assume papel estratégico.

Nesse contexto, entende-se que potencialmente os CMA podem vir a contribuir para a gestão dos problemas socioambientais ${ }^{2}$ locais e, a um só tempo, fortalecer a sociedade civil e o interesse público no interior do aparelho de Estado, de modo a colocar na pauta de suas discussões as questões sociais e ambientais sob a lógica da sustentabilidade democrática, via articulação de soluções técnicas e sociais, diferentemente da lógica do mercado que privilegia, sobremaneira, a adoção de procedimentos que dissociam as questões ambientais dos problemas sociais, especialmente no que remete à não problematização dos padrões de produção e consumo em vigência.

0 presente trabalho, portanto, visa à reflexão sobre a atuação dos CMA no campo da EA, tomando por referente teórico-conceitual tanto as recomendações advindas de Conferências Internacionais como de Tbilisi (1997) e do Tratado de Educação Ambiental para Sociedades Sustentáveis e Responsabilidade Global (TEASS), quanto à consideração dos marcos jurídicos que regulam as políticas públicas de EA no Brasil. Do ponto de vista teórico-empírico, analisa estudos que versam sobre a criação, implantação e funcionamento institucional e político dos CMA no pais, exclusivamente no que remete à EA, identificados a partir da consecução de uma pesquisa mias extensa sobre esses órgãos colegiados (SOUZA; NOVICKI, 2010).

\section{A EA nas conferências internacionais sobre meio ambiente}

A partir dos anos de 1970, simultaneamente às conferências internacionais que discutiram a relação meio ambiente-desenvolvimento ${ }^{3}$, ocorreram cinco grandes eventos internacionais que gravitaram em torno da EA: a I Conferência Intergovernamental sobre Educação Ambiental (Tbilisi, em 1977), o II Congresso Internacional sobre Educação e Formação Ambientais (Moscou, em 1987), o Fórum das Organizações Não Governamentais e Movimentos Sociais (Rio de Janeiro, em 1992, em paralelo à Eco92), a III Conferência Internacional sobre Meio Ambiente e Sociedade: Educação e Consciência Pública para a Sustentabilidade (Thessaloniki, em 1997) e, por fim, a IV Conferência Internacional de Educação Ambiental (Ahmedabad, em 2007).

2 Considerando que inexistem problemas ambientais - esgotamento da natureza e poluição do meio ambiente (FOLADORI, 2001) - que não afetem os seres humanos, entendemos apropriado denominálos problemas socioambientais.

3 Conferência das Nações Unidas sobre Meio Ambiente Humano (CNUMAH), em 1972; Conferência das Nações Unidas para o Meio Ambiente e o Desenvolvimento (CNUMAD), em 1992; e Conselho Municipal de Desenvolvimento Sustentável (CMDS), em 2002. 
Do conjunto desses eventos, destacam-se aqui as recomendações advindas da Conferência de Tbilisi (UNESCO, 1997) e do TEASS, este último produzido pelo Fórum das Organizações Não Governamentais e Movimentos Sociais (TEASS, 1992), pois, diferente da lógica do mercado defendida pelo enfoque do desenvolvimento sustentável (CNUMAH, 1972; CNUMAD, 1992, 2001; UNESCO, 2005), têm como perspectiva a construção de sociedades sustentáveis.

$\mathrm{Na}$ Conferência de Tbilisi (UNESCO, 1997) foram definidos os objetivos, funções, estratégias, características, princípios e recomendações para a EA. A alínea "c" pertencente à Recomendação $n^{\circ} 1$ ajuda-nos a entender o porquê deste evento ser considerado um marco conceitual da EA crítica, especialmente quando afirma que:

um objetivo fundamental da educação ambiental é lograr que os indivíduos e a coletividade compreendam a natureza complexa do meio ambiente natural e do meio ambiente criado pelo homem, resultante da integração de seus aspectos biológicos, físicos, sociais, econômicos e culturais, e adquiram os conhecimentos, os valores, os comportamentos e as habilidades práticas para participar responsável e eficazmente da prevenção e solução dos problemas ambientais, e da gestão da questão da qualidade do meio ambiente (UNESCO, 1997, p. 98).

Esse objetivo é corretamente predicado por fundamental, pois foca os alicerces de uma proposta de EA crítica, podendo ser decomposto em três partes que se articulam para a superação da educação conservacionista, defendida pelos enfoques do desenvolvimento sustentável.

Primeiramente, ao fazer menção aos indivíduos e à coletividade, a EA proposta na Conferência de Tbilisi descarta a abordagem reducionista da relação indivíduosociedade, pautada no dualismo cartesiano que tende a desarticular o indivíduo do meio social, ou seja, a parte do seu todo. Este artifício, de caráter alienante, por um lado, culpabiliza, de maneira geral, todos os seres humanos pelos impactos ambientais, sem atribuir pesos específicos aos diferentes atores sociais (Estado, mercado, sociedade, indivíduo), e, por outro lado, revela o objetivo da educação conservacionista, pois entende "o problema ambiental como fruto de um desconhecimento dos princípios ecológicos [falta de informação] que gera 'maus comportamentos' nos indivíduos", cabendo a esta concepção de educação "criar 'bons comportamentos'" (LAYRARGUES, 2000, p. 89). Este enfoque "comportamentalista-individualista" leva seus adeptos a associarem a degradação ambiental ao crescimento populacional do planeta - um "limite externo" à sustentabilidade (FOLADORI, 2001) -, pois se a questão ambiental está relacionada ao comportamento dos indivíduos, quanto maior o seu número, maiores serão os problemas. 
Em segundo lugar, a Conferência de Tbilisi (UNESC0, 1997, p. 98) define como objetivo da EA "lograr que os indivíduos e a coletividade compreendam a natureza complexa do meio ambiente natural e do meio ambiente criado pelo homem, resultante da integração de seus aspectos biológicos, físicos, sociais, econômicos e culturais". Diferente da educação conservacionista que, através de outro reducionismo, privilegia os aspectos biológicos do meio ambiente/natureza (foco das soluções técnicas), a concepção de meio ambiente proposta por Tbilisi (UNESCO, 1997) abrange os recursos naturais do planeta, as instituições e valores criados historicamente pela ação social do homem e, principalmente, a tensão existente entre ambos (esgotamento e poluição dos recursos naturais/meio ambiente). Esta concepção dialética da relação Homem-meio ambiente, ou relação do metabolismo sociedade-meio ambiente, explicita claramente a necessidade de se incorporar as diferentes dimensões da questão ambiental de modo interdisciplinar (ciências naturais e humanas), tanto na resolução dos problemas ambientais, quanto nas atividades de pesquisa e ensino sobre questões situadas na interface das temáticas educacional e ambiental, como a EA. Permite, ainda, colocar em xeque a sociedade que causa e lucra com a miséria humana e com o esgotamento/poluição do meio ambiente/natureza, pois dialeticamente desloca do individuo para a sociedade (da parte para o todo) as origens da degradação ambiental e da desigualdade social, que exigem, além de soluções técnicas e econômicas, 0 questionamento das relações sociais de produção vigentes, visando à construção de sociedades sustentáveis e não de um pretenso desenvolvimento sustentável.

Tbilisi (UNESCO, 1997), em terceiro lugar, recomenda que os conteúdos conceituais, procedimentais e atitudinais, envolvidos na concepção de EA em questão, devam ter como finalidade a resolução de problemas ambientais locais, apontando para a importância da relação teoria-prática ou reflexão-ação nesse processo, de modo a contribuir para a participação social na esfera pública.

Em sintese, Tbilisi (UNESCO, 1997) contribui para a reflexão em torno da compreensão e transformação da realidade socioambiental, de um lado, apontando a necessidade de se superar a alienação do homem em relação à natureza e à sociedade, através da consciência de que somos "naturalmente humanos" e "humanamente naturais" (MÉSZÁROS, 2006, p. 19) ou seja, por intermédio da consciência de nossa dupla (e inalienável) determinação natural e social, e, de outro lado, ressaltando a importância da participação da sociedade civil no processo decisório de formulação e implementação de políticas públicas e práticas sociais, que visem ao pleno exercício da cidadania.

Na I Jornada Internacional de Educação Ambiental, que culminou no Fórum das Organizações Não Governamentais e Movimentos Sociais, evento paralelo à ECO-92, foi produzido o TEASS, anteriormente mencionado. Na Introdução desse documento é destacada a importância da EA, entendida como processo educativo transformador e permanente na "formação de valores e na ação social" para a criação de "sociedades sustentáveis e equitativas", baseadas "no respeito a todas as formas de vida" (TEASS, 1992, p. 1). 
O TEASS (1992) gera um ponto de inflexão no debate sobre a sustentabilidade, pois promove o deslocamento do desenvolvimento sustentável para as sociedades sustentáveis, o que fica mais claro quando o documento relaciona ao modo de produção capitalista as causas, simultaneamente, da degradação ambiental e da desigualdade social, identificando, ainda, a alienação e a falta de participação como desafios da EA:

As causas primárias de problemas como o aumento da pobreza, da degradação humana e ambiental e da violência podem ser identificadas no modelo de civilização dominante, que se baseia em superprodução e superconsumo para uns e em subconsumo e falta de condições para produzir por parte da grande maioria [...] (TEASS, 1992, p. 1).

0 Tratado em questão apresenta, dentre os seus princípios, uma definição de EA para as sociedades sustentáveis distante de uma educação conservacionista, comportamentalista-individualista ou articulada à noção de desenvolvimento sustentável, na medida em que considera que a educação consiste num direito de todos, e que a EA "deve ter como base o pensamento crítico e inovador, em qualquer tempo ou lugar, em seus modos formal, não formal e informal, promovendo a transformação e a construção da sociedade ${ }^{4}$, explicitando, mais adiante, que a EA "não é neutra, mas ideológica" ${ }^{15}$, por isso mesmo corresponde a um ato político, devendo, portanto, "tratar as questões globais críticas, suas causas e interrelações em uma perspectiva sistêmica, em seu contexto social e histórico"6.

0 TEASS destaca com isto que a EA para as sociedades sustentáveis deve estimular e potencializar o poder das diversas populações, enfatizando os problemas locais em suas atividades e as devidas conexões com a realidade planetária, objetivando, assim, a conscientização para a transformação da realidade, inclusive de modo a também sensibilizar as populações para que "constituam Conselhos Populares de Ação Ecológica e Gestão do Ambiente visando investigar, informar, debater e decidir sobre problemas e políticas ambientais"7.

Consolidando argumentos, entendemos que as Recomendações de Tbilisi e do TEASS contrapõem-se à lógica do mercado, ou seja, à subsunção do trabalho e da natureza ao processo de acumulação capitalista, conforme preconizam as grandes conferências internacionais que discutiram o binômio desenvolvimento econômico-meio ambiente (desenvolvimento sustentável). Isto significa que Tbilisi e o TEASS entendem que as propostas de sustentabilidade devem subordinar-se à lógica social, ao processo democrático, e não somente aos interesses da classe social hegemônica (capitalistas).

\footnotetext{
4 TEASS. Tratado de educação ambiental para sociedades sustentáveis e responsabilidade global. Rio de Janeiro, 1992. p. 2.

Id., Ibid.

Id., Ibid.

Id., Ibid., p. 4.
} 
Sob essas perspectivas, a educação para sociedades sustentáveis (EA critica) assumiria dois grandes desafios: i) a construção de uma consciência ambiental, entendida, por um lado, como compreensão de que somos naturalmente humanos e humanamente naturais (dupla determinação natural e social) e, por outro, enquanto conhecimento do funcionamento da natureza, da sociedade, e das suas articulações; e, ainda, ii) a organização e mobilização dos trabalhadores com vistas à participação social nos processos decisórios de formulação e implementação de políticas públicas (NOVICKI, 2007b; LOUREIRO, 2007; LOUREIRO et al., 2009), que têm nos CMA (União, Estados e Municípios) um canal potencialmente privilegiado, também para esta finalidade, já que pode visar à transformação das demandas sociais e ambientais em políticas efetivas, bem como encaminhar os conflitos ambientais entre os interesses privados e o bem comum: o meio ambiente.

\section{A EA nas políticas públicas brasileiras}

No Brasil, a inserção da temática ambiental nos espaços formal e não formal de ensino $^{8}$ se faz notar tanto em textos como o da CF (BRASIL, 1988), quanto na esfera das políticas diretamente vinculadas à questão ambiental. Neste último caso, destacam-se a Lei $n^{\circ} 6.938$ (BRASIL, 1981), instituidora da PNMA, anterior àquela Carta, e, quase duas décadas após, a Lei $n^{\circ} 9.795$ (BRASIL, 1999) que implantou a Política Nacional de Educação Ambiental (PNEA), em seguida regulamentada pelo Decreto $n^{0} 4.281$ (BRASIL, 2002).

No âmbito da CF (BRASIL, 1988), em seu Artigo 225', o meio ambiente é entendido como "bem de uso comum do povo", cabendo ao poder público e à coletividade a responsabilidade pela preservação ambiental. Contudo, a EA, concebida como uma das formas que pode vir a assegurar o direito de acesso a esse bem é tratada (BRASIL, 1988, §1º, Inciso VI), como incumbência tipicamente atinente ao poder público (QUINTAS, 2004), sem menção à coletividade. Este poder visaria à promoção da EA "em todos os níveis de ensino" e, ainda, em termos da "conscientização pública para a preservação do meio ambiente", ou seja, sob perspectiva formal e não formal de EA9 .

Essas abordagens proporcionadas pela CF (BRASIL, 1988) à questão ambiental e à EA já se faziam notar, desde 1981, na PNMA (BRASIL, 1981), embora não esteja claro nessa lei a quem caberia tal encargo, conforme veio a ser explicitado mais tarde na Constituição, enquanto responsabilidade do próprio poder público.

8 Segundo Gohn (2006) a educação formal é aquela que se desenvolve dentro das instituições escolares, em ambientes normatizados, regulamentados por lei e também pela via da certificação. A educação não-formal ocorre no "mundo da vida, fora daqueles espaços, mediante um processo interativo intencional, capacitando "os indivíduos a se tornarem cidadãos do mundo, no mundo." " (GOHN, 2006, p. 29). Sua finalidade é abrir janelas de conhecimento sobre o mundo que circunda os indivíduos e suas relações sociais". Veja-se também Gohn (2001).

9 É importante observar que as expressões educação formal e não-formal não constam da CF (BRASIL, 1988) e da PNMA (BRASIL, 1981), sendo mencionadas apenas nos Artigos $9^{\circ}$ e $13^{\circ}$ da PNEA (BRASIL, 1999). 
Se, por um lado, a CF (BRASIL, 1988) avança sobre a PNMA em termos do envolvimento da sociedade civil como um dos protagonistas da EA, curiosamente expõe certo retrocesso em relação à Lei ${ }^{0} 6.938$ (BRASIL, 1981), pelo fato de considerar como objetivo da EA a "preservação do meio ambiente" (BRASIL, 1988), ou seja, por sinalizar uma concepção de educação conservacionista, em contraposição a uma proposta de EA focada na capacitação da sociedade civil, de modo a contribuir para a "participação ativa na defesa do meio ambiente" (BRASIL, 1981), abordagem que, sob uma primeira leitura, se aproximaria da perspectiva crítica de EA. Todavia, observa-se que a PNMA espelha um entendimento sobre o meio ambiente enquanto "conjunto de condições, leis, influências e interações de ordem física, química e biológica, que permite, abriga e rege a vida em todas as suas formas" (BRASIL, 1981), vertente aqui tomada por reducionista, pois não menciona suas dimensões social, política, cultural e econômica. Emerge disto uma contradição que se expressa pela tensão entre uma EA que poderia ser considerada potencialmente crítica, pautada na participação social, e uma concepção de meio ambiente restrita aos seus aspectos eminentemente naturais, característica central da educação conservacionista, ambas atinentes a um mesmo discurso.

Em larga medida, será na PNEA (BRASIL, 1999) que se manifestarão abordagens que irão sugerir certa proximidade em relação às vertentes criticas tanto sobre 0 meio ambiente (VELASCO, 2000; 2002), quanto propriamente a respeito da EA. No primeiro caso, por considerar existir uma relação de interdependência entre os seres humanos e a natureza/meio ambiente ${ }^{10}$, enquanto que, em termos da EA, por defender a participação social, individual e coletiva para os debates em torno da questão ambiental e a formulação e execução de politicas públicas e práticas sociais.

Conforme apontado por Layrargues (2002), entretanto, a institucionalização da PNEA se constituiu de modo precoce, isto em decorrência, por exemplo, da insuficiência dos debates políticos e sociais qualificados sobre a temática e, ainda, em função da incipiência do conhecimento teórico-conceitual a seu respeito. Um dos reflexos desta precocidade se expressa na concepção de EA que, por estar voltada para a conservação do meio ambiente ${ }^{11}$, se funda numa perspectiva dita naturalista, afastando-se, portanto, das correntes ditas críticas, ou seja, acabando por olhar "mais para a Natureza do que para a Sociedade" (LAYRARGUES, 2002, p. 11).

10 De acordo com a PNEA (BRASIL, 1999), o meio ambiente deve ser considerado em sua totalidade, levando em conta "a interdependência entre o meio natural, o sócio-econômico e o cultural, sob o enfoque da sustentabilidade”, abordagem articulada ao enfoque de cunho socioambiental, coeso, por exemplo, às recomendações de Tbilisi (UNESCO, 1997) e do TEASS (1992).

11 Em seu Artigo $1^{\circ}$, a PNEA (BRASIL, 1999, grifo nosso) entende por EA “os processos por meio dos quais o indivíduo e a coletividade constroem valores sociais, conhecimentos, habilidades, atitudes e competências voltadas para a conservação do meio ambiente, bem de uso comum do povo, essencial à sadia qualidade de vida e sua sustentabilidade”. 
Alguns anos após a criação da PNEA, sua regulamentação veio a ocorrer pela via do Decreto ${ }^{0} 4.281 / 2002$ (BRASIL, 2002) e, de modo distinto daquela lei, decorreu de intensas discussões realizadas no âmbito da Câmara Técnica Temporária de Educação Ambiental, especialmente constituída pelo CONAMA para esta finalidade (UEMA, 2009). Em seu Artigo 10, este decreto determina que a execução da PNEA consiste em responsabilidade dos órgãos e entidades integrantes do SISNAMA, das instituições educacionais públicas e privadas dos sistemas de ensino, dos órgãos públicos da União, Estados, Distrito Federal e Municípios, das Organizações Não Governamentais (ONG), entidades de classe, meios de comunicação e demais segmentos da sociedade ${ }^{12}$.

A implementação da PNEA, em nível nacional, tem-se dado por intermédio de duas pastas ministeriais e por meio de instrumentos de regulação específicos. De um lado, é implementada pela via do Programa Nacional de Educação Ambiental (PRONEA) (BRASIL, 2005), atinente tanto ao Ministério do Meio Ambiente (MMA), quanto ao Ministério da Educação (MEC), e, de outro, por intermédio de ações específicas do próprio MEC, como a edição, para o Ensino Fundamental, dos Parâmetros Curriculares Nacionais (PCN) (BRASIL, 1997a, 1997b, 1998a, 1998b) e do Programa Parâmetros em Ação (BRASIL, 2001), dos Referenciais Curriculares Nacionais da Educação Profissional de Nível Técnico (BRASIL, 2000) e, por fim, da Proposta de Diretrizes Curriculares Nacionais para a Educação Ambiental (BRASIL, 2007a).

No âmbito do MMA, o PRONEA teve sua primeira edição em 1994 (BRASIL, 1994), tomando por referência a Conferência de Educação Ambiental de Tbilisi (UNESCO, 1997), sendo que somente em 2005 veio a vigorar a sua atual edição (BRASIL, 2005), que aprofunda questões relativas ao papel da EA no processo de empoderamento dos grupos sociais.

Na esfera do PRONEA, que resultou de uma ampla consulta pública, é defendido que a participação da sociedade civil deve ocorrer, em especial, nos trâmites decisórios sobre $o$ acesso aos recursos ambientais e seu uso, assim como no fortalecimento das ditas práticas comunitárias sustentáveis, pois aponta a necessidade de a EA superar, de um lado, as "assimetrias nos planos cognitivos e organizativos, já que a desigualdade e a injustiça social ainda são características da sociedade" e, de outro, as práticas restritas à "disponibilização de informações" (BRASIL, 2005, p. 34).

De acordo com Sorrentino e outros (2005), a execução do PRONEA pelo MMA, de caráter não formal, ocorre pela via dos Programas Municípios Educadores Sustentáveis e Formação de Educadores Ambientais, ambos desenvolvidos em parceria com as Comissões Interinstitucionais de Educação Ambiental (CIEA) ${ }^{13}$. Estes Programas abarcam quatro pro-

12 Ainda no que remete ao Decreto $n^{\circ} 4.281$ (BRASIL, 2002), a partir de julho de 2003, foi criado pelo Governo Federal o chamado "Órgão Gestor da Política Nacional de Educação Ambiental”, o que pode favorecer a coordenação das ações do MMA e do MEC no campo da EA, com vistas à superação da fragmentação das políticas setoriais de educação e de meio ambiente geradas por essa dualidade ministerial.

13 As CIEA são compostas por redes de educação ambiental, governos estaduais e municipais, universidades, consórcios municipais ou comitês de bacia hidrográfica, gerências do IBAMA e outros órgãos públicos federais e estaduais (SORRENTINO et al., 2005). 
cessos educacionais básicos, a saber: i) formação de educadores ambientais, via parceiros chancelados pelo MMA, tendo por estratégia a articulação, a orientação e o apoio a Coletivos Educadores ${ }^{14}$; ii) educomunicação socioambiental, entendendo-a enquanto produção e distribuição de material educacional, campanhas de educação ambiental e uso de meios de largo alcance; iii) ações ou projetos em escolas, praças públicas, viveiros, hortas comunitárias, tomados como estruturas educadoras; e, por fim, iv) participação democrática em foros e demais espaços de participação sociopolítica.

Já a execução do PRONEA pelo MEC, via Coordenação Geral de Educação Ambiental (CGEA), se pauta no desenvolvimento de quatro ações fundamentais e permanentes no espaço escolar, denominadas: Conferência Nacional de Meio Ambiente (CNMA), Formação Continuada de Professores e Estudantes, Inclusão Digital com Ciência de Pés no Chão, Educação de Chico Mendes, todos envolvendo secretarias de educação estaduais e municipais, professores, alunos, comunidade escolar, sociedade civil e universidade (SORRENTINO et al., 2005).

Do ponto de vista das ações especificas do MEC, inicialmente cabe apontar a edição dos Parâmetros Curriculares Nacionais (PCN), pertinente ao Ensino Fundamental, que fornecem orientações voltadas à inserção da temática ambiental no seu primeiro (BRASIL, 1997a, 1997b) e segundo segmentos (BRASIL, 1998a, 1998b). Na esfera da Educação Infantil, essa inclusão é preconizada pelo Referencial Curricular Nacional relativo a esse nivel de ensino (BRASIL, 1998c). Grosso modo, essas recomendações visam a contribuir para o desenvolvimento de uma consciência que favoreça a participação social nos processos decisórios de formulação e implementação das políticas públicas na área, tanto na Educação Infantil, quanto no Ensino Fundamental, estando prevista para ocorrer por intermédio de três Blocos de Conteúdos que visam, respectivamente, a levar o aluno a: i) conhecer os principais conceitos da temática ambiental referidos aos aspectos biológicos do meio ambiente; ii) entender a relação que o Homem e a sociedade estabelecem com a

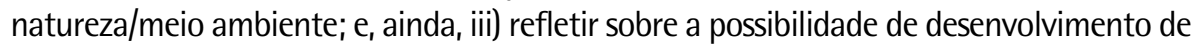
ações que visem, em caráter preventivo ou corretivo, à resolução (técnica, econômica, legal, entre outras) dos problemas ambientais (BRASIL, 1998b; 1998c) ${ }^{15}$.

14 Entende-se por Coletivos Educadores o conjunto de instituições com capacidade instalada para operar processos de formação em EA, tais como: universidades, movimentos, ONG, federações sindicais, pastorais, secretarias de Estado, Núcleos de Educação Ambiental (NEA) do IBAMA e da Empresa Brasileira de Pesquisa Agropecuária (Embrapa) e, ainda, órgãos estaduais e federais de pesquisa e extensão, entre outros (SORRENTINO et al., 2005).

15 Sobre os problemas relacionados à formulação dos PCN em geral, veja-se, por exemplo, Moreira (1999) e Universidade Federal Rio Grande do Sul (1999). Já em relação à questão da transversalidade, veja-se Macedo (1999) que, além de problematizar a ideia de currículo disciplinar nos termos de sua suposta incapacidade de dar conta da realidade pluridimensional, coloca em questão, de um lado, a necessidade de criação de mecanismos integradores das diferentes disciplinas e, de outro, a própria superação deste tipo de estruturação curricular. Cabe ainda destacar Álvarez e outros (2002) que, embora não trate da realidade brasileira em particular, reúne reflexões teóricas e experiências sobre o conceito e a potencialidade educativa dos temas transversais nas instituições educacionais espanholas, em diferentes níveis e modalidades de ensino. 
Em 2001, o MEC publica o Programa Parâmetros em Ação (BRASIL, 2001) que propõe-se a contribuir para a formação continuada de professores do Ensino Fundamental, de modo que o docente promova a abordagem da temática ambiental no conjunto das disciplinas deste nivel de ensino. Do ponto de vista curricular, este programa considera que a questão ambiental se encontra marcada por certa complexidade e especificidades, impondo a necessidade de tratá-la pedagogicamente de forma integrada às demais disciplinas, afirmando, portanto, a ideia da transversalidade na sua implementação escolar.

Seis anos após o lançamento dos PCN/Tema Transversal: Meio Ambiente, estudo elaborado pelo Instituto Nacional de Estudos e Pesquisas Educacionais Anísio Teixeira (INEP) procurou traçar um diagnóstico da EA no Ensino Fundamental brasileiro, a partir de dados levantados pelo Censo Escolar (VEIGA; AMORIM; BLANCO, 2005). Ao considerar o periodo entre 2001 e 2004, o documento sinaliza um crescimento acelerado e abrangente da disseminação da EA formal: enquanto em 2001, o número de escolas que informaram desenvolver algum tipo de EA estava em torno de 115 mil (71,7\% das escolas do pais), em 2004, esse número passou para 152 mil $(94,9 \%)$, apontando um crescimento de $32 \%$, caracterizado, especialmente, pela inserção da temática ambiental nas várias disciplinas, conforme preconizado por aqueles parâmetros, e, em menor escala, pela promoção de projetos e disciplinas especiais. Esta pesquisa veio mais tarde motivar a realização de uma outra investigação que, por intermédio de abordagem, agora qualitativa, visou a aprofundar o conhecimento sobre as práticas de EA levadas a efeito por escolas públicas e privadas de Ensino Fundamental (BRASIL, 2006a).

Já em termos do Ensino Médio Profissional (Área de Meio Ambiente), os três Blocos de Conteúdos destinados à inserção transversal curricular da EA, acima mencionados, são agora considerados funções ou competências a serem desenvolvidas na formação do Técnico em Meio Ambiente (BRASIL, 2000), objetivando: i) identificar e caracterizar os processos de conservação e de degradação natural; ii) avaliar os diferentes impactos ambientais decorrentes da exploração dos recursos naturais e das atividades produtivas em geral, na perspectiva do desenvolvimento sustentável, e, por último, iii) aplicar os princípios de prevenção e correção dos impactos ambientais (legislação, gestão ambiental, educação ambiental e uso de tecnologias.

0 exame crítico desses Referenciais Curriculares (BRASIL, 2000), inicialmente revela a sua articulação com perspectivas orientadas pelo modelo de competências, considerado um aspecto central nas reformas educacionais dos anos 1990, particularmente no âmbito da Educação Profissional, tendo como principal justificativa a inadequação do sistema educacional à realidade do mercado de trabalho. Tal perspectiva também se faz notar nas concepções de sustentabilidade e de meio ambiente concernentes àquele documento. No primeiro caso, por privilegiar soluções técnicas, conforme preconizado pelas conferências internacionais que discutiram o binômio desenvolvimento-meio ambiente, ou seja, por estar orientada segundo a matriz discursiva da ecoeficiência (ACSELRAD; LEROY, 1999; DELUIZ; NOVICKI, 2004), segundo a qual o desenvolvimento sustentável seria alcançado através de tecnologias limpas, conforme anteriormente mencionado. Já no segundo caso, a concepção de meio ambiente presente revela uma abor- 
dagem reducionista e antropocêntrica, também já caracterizada, que enfatiza os aspectos biológicos do meio ambiente, pois o entende: "como 'tudo aquilo que nos cerca', englobando os elementos da natureza como a fauna, a flora, o ar, a água, sem esquecer os seres humanos" (BRASIL, 2000, p. 15). A nosso ver, o meio ambiente não pode ser reduzido exclusivamente à esfera de "tudo aquilo que nos cerca", como algo exterior, que mantém conosco uma relação de exterioridade, posto que somos constituídos fisicamente por elementos naturais, como água, ferro, zinco, oxigênio, entre outros.

Ainda em termos das ações específicas do MEC na implementação da PNEA, cabe apontar, finalmente, a Proposta de Diretrizes Curriculares para a Educação Ambiental (BRASIL, 2007a) encaminhada ao Conselho Nacional de Educação (CNE), com a finalidade de garantir a abordagem transversal e interdisciplinar da temática ambiental em todos os níveis de ensino e, particularmente, no curso de Pedagogia e nas diferentes licenciaturas. A rigor, trata-se de mais uma iniciativa visando à implementação da política educacional proposta há uma década (BRASIL, 1997a, 1997b, 1998a, 1998b), agora por intermédio de proposta de formação inicial de professores. Estes documentos apresentam, em síntese, alguns encaminhamentos que tratam da inserção da dimensão ambiental nos diferentes cursos de Ensino Superior e que, no curso de Pedagogia e nas diferentes licenciaturas da Educação Superior, a EA consista em "atividade curricular, disciplina ou projetos interdisciplinares" (BRASIL, 2007a, p. 1). Cabe ainda destacar que esta Proposta muito se aproxima do cenário revelado na pesquisa desenvolvida pelo INEP (VEIGA; AMORIM; BLANCO, 2005), anteriormente mencionada, em que foi constatada a inserção da temática ambiental no Ensino Fundamental através de três modalidades: nas disciplinas, nos projetos e nas disciplinas especiais.

\section{A EA na esfera dos conselhos de meio ambiente no Brasil}

Em meio às expectativas iniciais sobre o processo de redemocratização do Brasil, verifica-se, a partir dos anos 1970, o surgimento da legislação e de órgãos ambientais nas diferentes esferas governamentais, cabendo destacar a criação, em 1973, da Secretaria Especial de Meio Ambiente (SEMA) como o primeiro órgão oficial do país dedicado à gestão do meio ambiente, vinculado ao Ministério do Interior (IBGE, 2008). Alguns anos após, em 31 de outubro de 1981, veio a ser sancionada a Lei $n^{\circ}$ 6.938, instituidora da Política Nacional de Meio Ambiente (PNMA) (BRASIL, 1981), definindo os seus fins e mecanismos de formulação e aplicação ${ }^{16}$. Esta lei criou 0

16 Embora a PNMA (BRASIL, 1981) estivesse pautada no princípio do compartilhamento e da descentralização das responsabilidades pela proteção ambiental, não apenas entre os entes federados, mas também em relação à sociedade civil, a União passará, em larga medida, a centralizar a regulação das questões ambientais, cabendo aos órgãos ou entidades estaduais a execução de programas, projetos e o controle e fiscalização de atividades degradantes da qualidade ambiental, enquanto que às instâncias municipais será indicado o controle e fiscalização local dessas atividades (Artigo $6^{\circ}$, inciso IV e V). A ação regulamentadora dos Estados e Municípios assumirá caráter supletivo e complementar em relação à União, sendo também facultado aos Municípios a elaboração de normas relativas à sua área de jurisdição, observadas as normas e os padrões federais e estaduais (BRASIL, 1981, art. $6^{\circ}, \S 1^{\circ}, \$ 2^{\circ}$ ). 
Sistema Nacional de Meio Ambiente (SISNAMA), implicando, entre outros aspectos, a constituição do Conselho Nacional de Meio Ambiente (CONAMA) ${ }^{17}$.

A estruturação do SISNAMA se portaria similarmente a uma rede de organizações, a ela cabendo a formulação de políticas públicas de meio ambiente, a articulação entre as instituições componentes do sistema em âmbitos federal, estadual e municipal e a execução dessas políticas por meio dos órgãos competentes. Nessas três esferas federadas, os órgãos ambientais passam a ter, portanto, a responsabilidade de promover a troca de informações, a formação da consciência ambiental, a fiscalização e o licenciamento ambiental ${ }^{18}$, além da criação de Comissões Tripartites, conselhos, órgãos e fundos de meio ambiente, buscando, ainda, estabelecer uma política ambiental integrada, no sentido de incluir essa questão nas demais políticas de governo (BRASIL, 2006a).

Com isso, o CONAMA vai assumir centralidade na gestão da ambiental nacional, afigurando-se num órgão colegiado de caráter deliberativo e consultivo do MMA, criado com a finalidade proclamada de "assessorar e propor diretrizes e políticas ambientais e de deliberar sobre normas e padrões para um ambiente ecologicamente equilibrado e essencial à sadia qualidade de vida" (BRASIL, 2006b, p. 11).

Nos Estados e Municípios, a estrutura do SISNAMA tenderá a se reproduzir, implicando que o órgão central adquira "o formato de secretaria, departamento ou fundação de meio ambiente" (BRASIL, 2006a, p. 39), podendo ser exclusivo ou compartilhado com outras áreas, demandando constituição dos Conselhos Estaduais de Meio Ambiente (CEMA) e dos Conselhos Municipais de Meio Ambiente $(\mathrm{CMMA})^{19}$, órgãos paritários passiveis de desempenharem competências consultiva, deliberativa, normativa e fiscalizadora ${ }^{20}$.

Entretanto, do ponto de vista empírico, é possivel afirmar que pouco se sabe a respeito do funcionamento institucional, político e normativo desses conselhos. Amplo e exaustivo levantamento documental realizado (SOUZA; NOVICKI, 2010) revelou que a

17 Nesse momento (1970-1980), os esforços em torno da gestão ambiental se caracterizavam mais por políticas de controle da poluição e zoneamento industrial, de caráter defensivo, do que, a exemplo das décadas anteriores (1930-1970), no protecionismo e na noção de conservação dos recursos naturais, perspectivas que mais recentemente vieram a dar lugar ao binômio ecodesenvolvimento-sustentabilidade (NEDER, 1994).

18 Entende-se por licenciamento o "procedimento administrativo pelo qual o órgão de meio ambiente avalia e concede licença de localização, instalação, ampliação e operação de empreendimentos e atividades que utilizem recursos naturais e possam causar danos ou impactos ambientais" (BRASIL, 2006a).

19 Além das instâncias federal e estaduais desses conselhos (CONAMA e CEMA), é importante sinalizar que apenas 47,6\% (2.650) dos Municipios brasileiros indicam possuir CMMA, ou seja, menos do que a metade dessas localidades possuem órgão que permite a representação da sociedade civil no debate público sobre as questões ambientais (IBGE, 2008).

20 De acordo com o IBGE (IBGE, 2008), a competência consultiva se caracteriza pelo estudo e indicação de ações ou políticas sobre determinada matéria que venha a ser submetida ao CMMA; a deliberativa implica exercício do poder decisório; a fiscalizadora o acompanhamento e controle da implementação e funcionamento de políticas e/ou a administração de recursos relativos à sua área de atuação; enquanto que a competência normativa o estabelecimento de normas e diretrizes para as políticas e/ou administração de recursos relativos à sua área de atuação. 
produção científica sobre os CMA no Brasil ${ }^{21}$, nas três esferas federadas, é escassa e incipiente, limitada a 27 estudos, refletindo a pouca valorização, em geral, social, e, em particular, acadêmica, relacionada a esses espaços. Nesse universo, os estudos que enfocam os CMMA representam cerca de $2 / 3$ da produção científica selecionada $(63 \%, 17)$, seguidos dos que se voltam para os CEMA $(26 \%, 7)$ e, com baixissima incidência, os estudos que versam sobre a instância federal desses conselhos (11\%, 3), o CONAMA.

A incipiência em questão não se faz notar apenas do ponto de vista quantitativo, uma vez que é igualmente reduzida a abordagem da EA em meio ao exame do funcionamento institucional ou político desses conselhos. De modo tímido, a questão da EA surge em meio às discussões sobre a capacitação dos membros conselheiros enquanto atividade que pode contribuir tanto, de modo instrumental, para a redução de seu deficit de conhecimentos na área, quanto, em termos críticos, para o desenvolvimento de uma consciência ambiental local. Apesar disto, percebe-se que, de modo geral, os CMA são poupados do exame de suas possibilidades de atuação na área da EA, o que nos leva a considerar este aspecto como uma importante questão, da qual quase nada se sabe, e que, por isso mesmo, não pode ser perdida de vista na realização de pesquisas sobre esses órgãos, conforme levado a efeito por Noara (2007), Noara e Florit (2007) e Castro (2003).

0 estudo de Noara (2007) - dissertação de mestrado que veio a ser publicada em periódico da área (NOARA; FLORIT, 2007) - revela, entre outros aspectos, que o entendimento dos conselheiros dos CMMA de Blumenau (SC) e Indaial (SC) sobre a EA, não se apresenta suficientemente crítico, reduzindo esta modalidade de educação ao mero conhecimento ou informações (cursos de capacitação, campanhas de conscientização, entre outros) sobre o uso dos recursos naturais, não contemplando, portanto, o necessário questionamento acerca dos padrões de consumo e de desenvolvimento que vêm afetando o meio ambiente ${ }^{22}$.

Um outro importante trabalho, que toma por alvo central de análise a questão da capacitação técnica dos membros desses Conselhos, consiste na dissertação de mestrado de Castro (2003), por intermédio da qual a autora informa ter analisado o processo de criação, implantação e funcionamento do CMMA de São Paulo (SP), cobrindo as suas

21 Do ponto de vista de sua abrangência, o levantamento visou selecionar estudos que viessem a expor coesão em relação ao eixo temático "Conselhos de Meio Ambiente (CMA) no Brasil” e, em consequência, ao conjunto das categorias que naquele momento serviram à sua definição, notadamente no que remete aos CMA nas esferas nacional, estadual e municipal. Inventariaram-se obras, exclusivamente: i) circunscritas ao período 1981-2007; ii) de autoria ou co-autoria de pessoa física; iii) publicadas no Brasil e que não constituíssem tradução de obra originalmente publicada no exterior; iv) referentes a dissertações de mestrado e teses de doutorado, livros no todo e partes de livros, artigos publicados em periódicos e, ainda, trabalhos em Anais de eventos científicos.

22 Em termos gerais, Noara (2007) indica não ter distinguido em seu trabalho de pesquisa ações propositivas por parte desses CMMA articuladas à formulação de políticas públicas de proteção ambiental, a não ser de caráter pontual, em resposta às demandas emergenciais locais, cujas deliberações refletem o interesse particular dos seus membros conselheiros, embora tenham sido antecedidas por discussões tipicamente de ordem técnica. 
três primeiras gestões (1994-1999), de modo a examinar se os seus conselheiros consideram-se preparados para o exercício dessa função, as eventuais dificuldades por eles vivenciadas, além de buscar verificar se a EA é, de fato, entendida por eles enquanto meio de capacitação e de facilitação da participação social nesse órgão colegiado. Uma vez verificado que a capacitação assume papel de relevo no desempenho do CMMA de São Paulo, esse autor informa que a EA emerge em sua pesquisa enquanto meio privilegiado para este tipo de formação. Contudo, esclarece que o sentido da EA não deve restringir-se à mera instrumentalização da promoção do conhecimento e formação de atitudes e habilidades demandadas pelas atribuições conselheiras, mas também enquanto ação que pode favorecer o desenvolvimento de uma consciência ambiental voltada para a implementação de políticas públicas e o exercício da cidadania.

Inicialmente, é importante considerar que as possibilidades e limites da EA via CMA são fortemente determinados pelas contradições inerentes ao modo de produção capitalista, particularmente no que remete às relações entre trabalho e capital e entre este último e a natureza, relações essas que são internalizadas pelo Estado e, consequentemente, por esses conselhos, refletindo-se, a um só tempo, nas políticas públicas. A análise crítica dessas relações pode, portanto, pôr em xeque a viabilidade da sustentabilidade (ALTVATER, 1995; 1999; CHESNAIS; SERFATI, 2003) e da democracia (PRZEWORSKI, 1989; WOOD, 2006) sob o modo de produção capitalista.

Em seu conjunto, considerando as contradições inerentes ao modo de produção capitalista e o autoritarismo que caracteriza histórica e socialmente o processo político brasileiro, caberia aos CMMA, por intermédio, por exemplo, da EA, contribuirem para a superação da alienação existente, reintegrando o ser humano à natureza e à sociedade, de modo a superar os limites postos aos processos decisórios de formulação e de implementação de políticas públicas, especialmente de meio ambiente (NOVICKI, 2007b; LOUREIRO et al., 2009). Neste sentido, cabe indagar como os CMMA, através de suas competências e atribuições, podem encaminhar a resolução destas questões.

A Conferência de Tbilisi (UNESCO, 1997) considera como método de formação eficaz na EA a adoção de estratégias de aprendizagem que privilegiem a solução de problemas ambientais locais que, segundo Layrargues (1999), pode envolver duas abordagens teórico-metodológicas: a resolução de problemas ambientais como uma atividade-fim, priorizada por ecoempresários socioambientalmente responsáveis (ALMEIDA, 2002; HAWKEN; LOVINS; LOVINS, 1999), ou na perspectiva de constituir-se em atividade meio, nomeadamente em ação pedagógica (tema gerador) articulada à discussão sobre a relação sociedade-meio ambiente.

Podemos exemplificar essas distintas formas de aproximação da realidade através de uma ressignificação da conhecida metáfora do "efeito dominó": enquanto a resolução de problemas ambientais como atividade-fim concentra-se, através uni- 
camente de soluções técnicas, no último dominó caído - o fenômeno ou o problema ambiental (esgotamento e poluição da natureza/meio ambiente) -, a segunda perspectiva, a que encara a EA como meio privilegiado de discussão dos problemas que marcam a sociedade, tenta focalizar, além das soluções técnicas para os problemas ambientais, a totalidade do processo social que o gerou, ou seja, busca à sua essência nos termos do desvelamento dos conflitos que se estabelecem entre os interesses privados e o bem público (meio ambiente). Neste último caso, a atenção da EA se volta para as peças do dominó que caíram antes da última, pois o processo e suas causas passam a assumir centralidade nas ações de EA (NOVICKI, 2007a).

Assim, a par das soluções técnicas e legais, a EA consiste em um instrumento estratégico na reversão do quadro de degradação socioambiental, pois, sob uma perspectiva crítica, foca as suas causas e o empoderamento das comunidades envolvidas no conflito ambiental, com vistas à participação sociopolítica e à constituição e ao desenvolvimento, respectivamente, de identidade e ação coletivas na esfera pública como, por exemplo, passivel de ocorrer nos CMMA.

A EA, com isto, pode ser tomada como uma importante atribuição dos CMMA, espaços que, em paralelo ao conjunto de competências que os caracterizam, podem promover e manifestar-se sobre as diretrizes e a formulação, implementação e fiscalização da Política Municipal de EA nos espaços formal e não-formal de ensino, inclusive apoiando as iniciativas das comunidades e as campanhas nos meios de comunicação (BRASIL, 2006b).

Além disso, a transversalidade da temática ambiental - conforme preconizado nas conferências e nos documentos internacionais, na política educacional e na literatura crítica - não se deve restringir às disciplinas escolares, mas também perpassar o conjunto das políticas públicas. Neste sentido, o CMMA pode ter, dependendo do grau de mobilização da sociedade, um papel fundamental também na ambientalização das políticas setoriais, conforme preconizado no decreto que veio a regulamentar a PNEA (BRASIL, 2002) e, posteriormente, no PRONEA (BRASIL, 2005), significando que no organograma do executivo local a preocupação com a questão ambiental não fique restrita ao órgão ambiental ou que a EA seja assunto apenas de um departamento ou assessoria, o que atribuiria organicidade à temática ambiental na política governamental, fortalecendo a dimensão educativa da ação estatal.

No interior do aparelho de Estado, de modo específico, advoga-se também que os CMMA podem vir a impulsionar a implementação do Programa Agenda Ambiental na Administração Pública (A3P) (BRASIL, 2007b), que visa a estimular os gestores públicos a incorporar princípios e critérios de gestão ambiental em suas atividades rotineiras (mudança nos investimentos, compras e contratação de serviços pelo governo, gestão dos resíduos gerados e dos recursos naturais utilizados, entre outros), em especial por 
intermédio da EA. Esta viria, portanto, cumprir função formativa de recursos humanos nesse campo, por meio da realização de palestras, reuniões, exposições, oficinas de arte educação. Todavia, conforme assinalado por Barata, Kligerman e Minayo-Gomez (2007), o êxito da implantação da A3P encontra-se fortemente dependente do grau de engajamento do servidor público, inclusive dos seus gestores.

Contudo, uma importante atribuição dos CMMA, que tem demandado ações de EA consiste nos processos de licenciamento que, a partir da Resolução Conama ${ }^{\circ} 237$ (BRASIL, 1997c), veio a regular a atuação do Municipio no licenciamento ambiental local e, em função dos impactos ambientais do empreendimento licenciado passou-se a exigir, por força da própria PNEA (BRASIL, 1999) -, o desenvolvimento de EA visando, por um lado, a minorar esses impactos no cotidiano local e, por outro, a fortalecer a população para a reivindicação dos seus direitos sociais e ambientais. Nessa arena, passa a caber aos CMMA proporcionar as condições para o desenvolvimento e mobilização das capacidades necessárias para que grupos sociais exerçam o controle social da gestão ambiental pública (QUINTAS, 2004; GUIMARÃES, 2001).

Mais recentemente, alguns estudos vêm destacando as possibilidades e limites da EA no âmbito dos processos de licenciamento ambiental (LOUREIRO, 2009a; QUINTAS; GOMES; UEMA, 2005). Para Loureiro (2009b, p. 23), o licenciamento consiste num processo institucionalizado e de "atributo exclusivo do estado que busca, por meio de seus instrumentos legitimados, garantir certos padrões de desenvolvimento humano, social e de proteção e preservação ambiental, cujos critérios para execução são definidos segundo motivações politicas e econômicas e [por] parâmetros oriundos do conhecimento científico", o que denotaria a importância da EA nessas ações não apenas do ponto de vista oficial, decorrente das exigências legais, mas como ação sociopolítica articulada ao desenvolvimento de uma consciência social critica sobre as questões ambientais.

Ainda segundo Loureiro (2009b), a prática de EA vinculada ao licenciamento deveria perseguir, igualmente aos demais espaços formais e não formais de sua realização (JACOBI; TRISTÃO; FRANCO, 2009; JACOBI, 2003, 2005; REIGOTA, 2007; FISCHER, 2009; SORRENTINO et al., 2005, GUIMARAES; VASCONCELLOS, 2006), o exame crítico: i) das bases econômico-políticas do modo de produção capitalista contemporâneo, envolvendo, igualmente, aspectos concernentes aos seus custos "energéticos e ecológicos" (LOUREIRO, 2009b, p. 23); e ii) de suas relações com as especificidades culturais, ecológicas e de gestão do meio ambiente das várias esferas sociais, direta (por exemplo, os conselheiros dos CMMA) e indiretamente envolvidas com essas ações (a sociedade local). Por isto, passa a ser considerada fundamental a "organização de espaços e momentos de troca de saberes, produção de conhecimentos, habilidades e atitudes que gerem a autonomia dos sujeitos participantes em suas capacidades de escolher e atuar transformando as condições socioambientais de seus territórios" (LOUREIRO, 2009b, p. 23). 
Contudo, estudos teórico-empíricos como o de Serrão, Walter e Vicente (2009) evidenciam a existência de um limite não tão claro entre as práticas sociopolíticas voltadas para a emancipação social na esfera do licenciamento ambiental, especialmente pela via da EA, e as que se caracterizam pela tutela de determinados grupos e classes sociais, nas quais o empoderamento das comunidades envolvidas com este tipo de licenciamento ainda se mostra insuficiente ou meramente formal, no sentido de apenas estar cumprindo com as exigências legais em vigor, isto sob uma perspectiva por caracteristica instrumental.

\section{Considerações finais}

Mesmo em face dos entraves anteriormente expostos, conclusivamente entende-se que os CMA, especialmente em âmbito Municipal, podem vir a contribuir para a gestão dos problemas socioambientais e, a um só tempo, fortalecer a sociedade civil e o interesse público (meio ambiente como um bem comum) no interior do aparelho de Estado. Pela via, por exemplo, da promoção de programas, projetos e, em específico, atividade de EA, esses Conselhos poderiam vir a constituir-se num espaço favorável à superação da alienação existente, de modo que venham a favorecer, em larga medida, a superação dos limites postos aos processos decisórios de formulação e de implementação de políticas públicas de meio ambiente.

Contudo, a capacidade dos CMA de influenciarem a formulação, implementação e avaliação das políticas governamentais esbarram, entre outros aspectos, em disputas diversas que marcam o Estado brasileiro, materializando-se, por conseguinte, na própria estrutura e funcionamento dos órgãos responsáveis pelas diferentes políticas vinculadas à questão ambiental, isto nas três esferas federadas.

Essas contradições, conforme visto, presentes no ordenamento jurídico atinente às políticas de estado e governamentais, especialmente em termos da EA, se portam também enquanto expressão da problemática da implementação das políticas setoriais no Brasil (educação, saúde, habitação, obras, agricultura, indústria, cultura etc.), que caracterizam, em última instância, a ação estatal no enfrentamento das questões social e ambiental. Estas tendem a ocorrer de modo desarticulado e fragmentado, inclusive dificultando a participação da sociedade civil que, em face da multiplicidade de aparatos públicos e forças políticas envolvidas nas questões ambientais, acaba também por desconhecer os espaços para os quais as suas reivindicações podem ou devem ser encaminhadas.

Por outro lado, cabe afirmar que não basta ter consciência ambiental ou conhecimentos necessários para compreender e transformar a realidade socioambiental. Faz-se necessário, sobremaneira, a mobilização da sociedade em torno das questões ambientais, ação dificultada pela desconexão que se proporciona à temática ambiental em relação aos demais problemas cotidianos, o que se deve à internalização e 
reprodução de uma abordagem reducionista de meio ambiente (restrita aos seus aspectos biológicos), que aliena e forja uma falsa consciência ambiental, que desconsidera o trinômio homem-sociedade-meio ambiente em uma estrutura social fundada no trabalho alienado e na subordinação dos seres humanos e da natureza ao processo de acumulação capitalista.

Tais princípios encontram-se fortemente dependentes do sentido que se venha atribuir à $E A$, neste caso, no interior dos $\mathrm{CMA}$, e às práticas sociais que daí emergem, de forma a contribuir para a superação da leitura reducionista ou fragmentada da realidade por intermédio do desenvolvimento de um olhar e ação interdisciplinares, que permitam a compreensão e solução articulada dos problemas sociais e ambientais.

Com isto, é esperado que os CMA venham a ter a possibilidade de melhor contribuir para a formatação de demandas ao poder executivo da União, dos Estados e, especialmente, dos Municípios, de modo a articular as diferentes políticas setoriais relacionadas à questão ambiental, visando à resolução de problemas socioambientais locais, para além das visões reducionistas que gravitam em torno da falácia do desenvolvimento sustentável.

\section{Referências}

ACSELRAD, H.; LEROY, J-P. Novas premissas da sustentabilidade democrática. Rio de Janeiro: FASE, 1999. (Cadernos de Debate Brasil Sustentável e Democrático; 1).

ALMEIDA, F. O bom negócio da sustentabilidade. Rio de Janeiro: Nova Fronteira, 2002.

ALTVATER, E. Os desafios da globalização e da crise ecológica para o discurso da democracia e dos direitos humanos. In: HELLER, A. (org.). A crise dos paradigmas em ciências sociais e os desafios para o século XXI. Rio de Janeiro: Contraponto, 1999.

. O preço da riqueza. São Paulo: USP, 1995.

ÁLVAREZ, M. N. et al. Valores e temas transversais no currículo. Porto Alegre: Artmed, 2002. (Coleção Inovação Pedagógica, 5).

BARATA, M. M. L.; KLIGERMAN, D. C.; MINAYO-GOMEZ, C. A gestão ambiental no setor público: uma questão de relevância social e econômica. Ciência da Saúde Coletiva, Rio de Janeiro, v. 12, n. 1, p. 165-170, 2007.

BRASIL. Constituição (1988). Constituição da República Federativa do Brasil. Diário Oficial [da] República Federativa do Brasil. Brasilia, DF, 5 out. 1988. 
BRASIL. Decreto $n^{0}$ 4.281, de 25 de junho de 2002. Regulamenta a Lei ${ }^{\circ} 9.795$, de 27 de abril de 1999, que institui a Política Nacional de Educação Ambiental, e dá outras providências. Diário Oficial da União, Brasilia, DF, 26 jun. 2002.

Lei $n^{\circ} 6.938$, de 31 de outubro de 1981. Dispõe sobre a Política Nacional do Meio Ambiente, seus fins e mecanismos de formulação e aplicação, e dá outras providências. Diário Oficial [da] República Federativa do Brasil, Brasilia, DF, 2 set. 1981.

. Lei ${ }^{\circ}$ 9.394, de 20 de dezembro de 1996. Estabelece as Diretrizes e Bases da Educação Nacional. Diário Oficial [da] República Federativa do Brasil, Brasilia, DF, 23 dez. 1996.

. Lei $n^{0}$ 9.795, de 27 de abril de 1999. Dispõe sobre a educação ambiental, institui a Política Nacional de Educação Ambiental e dá outras providências. Diário Oficial [da] República Federativa do Brasil, Brasilia, 28 abr. 1999.

- Ministério da Educação. Secretaria de Educação Continuada, Alfabetização e Diversidade. Educação na diversidade: o que fazem as escolas que dizem que fazem educação ambiental. Brasília, DF, 2006a. (Coleção Educação para Todos. Série Avaliação, n. 6).

. Ministério da Educação. Secretaria de Educação Média e Tecnológica. Educação profissional: referenciais curriculares nacionais da educação profissional de nível técnico: área profissional: meio ambiente. Brasília, DF, 2000.

. Ministério da Educação. Secretaria de Educação Continuada, Alfabetização e Diversidade. Proposta de diretrizes nacionais para a educação ambiental. Brasilia, DF, 2007a.

- Ministério da Educação. Secretaria de Educação Fundamental. Parâmetros curriculares nacionais; primeiro e segundo ciclos do ensino fundamental: introdução aos parâmetros curriculares nacionais. Brasilia, DF, 1997a.

Parâmetros curriculares nacionais: primeiro e segundo ciclos do ensino fundamental: tema transversal meio ambiente e saúde. Brasilia, DF, $1997 \mathrm{~b}$.

. Parâmetros curriculares nacionais: terceiro e quarto ciclos do ensino fundamental: introdução aos parâmetros curriculares nacionais. Brasilia, DF, 1998a.

. Parâmetros curriculares nacionais: terceiro e quarto ciclos do ensino fundamental: tema transversal meio ambiente. Brasilia, DF, 1998 b. 
BRASIL. Referencial curricular nacional para a educação infantil. Brasília, DF, 1998c.

. Programa parâmetros em ação: meio ambiente na escola. Brasília, DF, 2001.

- Ministério do Meio Ambiente. Conselho Nacional de Meio Ambiente. Resoluções do CONAMA: resoluções vigentes publicadas entre julho de 1984 e maio de 2006. Brasília, DF, 2006 b.

BRASIL. Ministério do Meio Ambiente. Conselhos de meio ambiente do Brasil: agenda ambiental na administração pública. 4. ed. Brasília, DF, 2007 b.

. Ministério do Meio Ambiente. Instituto Brasileiro do Meio Ambiente.

Programa Nacional de Capacitação de Gestores Ambientais: política nacional de meio ambiente. Brasília, DF, 2006c. (Cadernos de formação, v. 1).

Programa nacional de capacitação de gestores ambientais: como estruturar o sistema municipal de meio ambiente. Brasília, DF, 2006d. (Cadernos de formação, v. 2).

. Programa nacional de educação ambiental. Brasilia, DF, 1994.

Ministério do Meio Ambiente. Diretoria de Educação Ambiental;

Ministério da Educação e Cultura. Coordenação Geral de Educação Ambiental. Programa Nacional de Educação Ambiental: ProNEA. 3. ed. Brasilia, DF, 2005.

. Resolução CONAMA no. 237, de 19 de dezembro de 1997. Dispõe sobre a revisão e complementação dos procedimentos e critérios utilizados para o licenciamento ambiental. Diário Oficial [da] República Federativa do Brasil, Brasilia, 22 dez. 1997c.

BURKET, P. Marx and nature: a red and green perspective. New York: St. Martin's Press, 1999.

CASTRO, M. D. L. Educação ambiental, capacitação e participação na formulação de políticas públicas ambientais: o caso do Conselho Municipal do Meio Ambiente e Desenvolvimento Sustentável de São Paulo. 2003. $128 \mathrm{f}$. Dissertação (Mestrado em Educação, Arte e História da Cultura) - Universidade Presbiteriana Mackenzie, São Paulo, 2003.

CHESNAIS, F.; SERFATI, C. "Ecologia" e condições físicas da reprodução social: alguns fios condutores marxistas. Crítica Marxista, São Paulo, n. 16, p. 1-40, mar. 2003. Disponivel em: <http://www.unicamp.br/cemarx/criticamarxista/ 16chesnais.pdf >. Acesso em: 6 jan. 2010. 
CNUMAD. Agenda 21: Conferência das Nações Unidas sobre meio ambiente e desenvolvimento. 3. ed. Brasilia, DF: Senado Federal, 2001.

. Declaração do Rio sobre meio ambiente e desenvolvimento. Brasilia, DF: MMA, 1992. Disponivel em: <http://www.mma.gov.br/port/sdi/ea/documentos/ convs/decl_rio92.pdf>. Acesso em: 25 jun. 2009.

CNUMAH. Declaração de Estocolmo sobre o ambiente humano. Estocolmo, 1972. Disponivel em: <http://www.educacaoambiental.pro.br/victor/unidades/ DeclaraAmbienteHumano.pdf>. Acesso em: 25 jun. 2009.

DELUIZ, N.; NOVICKI, V. Trabalho, meio ambiente e desenvolvimento sustentável: implicações para uma proposta de formação crítica. Boletim Técnico do SENAC, Rio de Janeiro, v. 30, n. 2, p. 18-29, maio/ago. 2004.

DIEGUES, A. C. S. Desenvolvimento sustentável ou sociedades sustentáveis: da crítica dos modelos aos novos paradigmas. São Paulo em Perspectiva, São Paulo, v. 6, n. 1-2, p. 22-29, jan./jun. 1992.

FISCHER, N. B. Educação não-escolar de adultos e educação ambiental: um balanço da produção de conhecimentos. Revista Brasileira de Educação, Rio de Janeiro, v. 14, n. 41, p. 370-385, 2009.

FOLADORI, G. Limites do desenvolvimento sustentável. Campinas: Ed.Unicamp, 2001.

GOHN, M. G. Educação não-formal, participação da sociedade civil e estruturas colegiadas nas escolas. Ensaio: avaliação e políticas públicas em educação, Rio de Janeiro, v. 14, n. 50, p. 27-38, jan./mar, 2006.

Educação não-formal e cultura política. 2. ed. São Paulo: Cortez, 2001 (Coleção Questões da Nossa Época, 71).

GUIMARÃES, M. Educação ambiental e gestão para a sustentabilidade. In: SANTOS, J. E.; SATO, M. (Org.). A contribuição da educação ambiental à esperança de Pandorra. São Carlos: Rima, 2001.

GUIMARÃES, M.; VASCONCELLOS, M. M. N. Relações entre educação ambiental e educação em ciências na complementaridade dos espaços formais e não formais de educação. Educação em Revista, Curitiba, n. 27, p. 147-162, 2006.

HAWKEN, P.; LOVINS, A.; LOVINS, H. Capitalismo natural: criando a próxima revolução industrial. São Paulo: Cultrix; Amana-Key, 1999. 
IBGE. Perfil dos municípios brasileiros: 2008. Rio de Janeiro, 2008.

JACOBI, P. R. Educação ambiental: o desafio da construção de um pensamento crítico, complexo e reflexivo. Educação e Pesquisa, São Paulo, v. 31, n. 2, p. 233-250, 2005.

. Educação ambiental, cidadania e sustentabilidade. Cadernos de Pesquisa, São Paulo, n. 118, p. 189-206, 2003.

JACOBI, P. R.; TRISTÃO, M.; FRANCO, M. I. G. C. A função social da educação ambiental nas práticas colaborativas: participação e engajamento. Cadernos CEDES, Campinas, v. 29, n. 77, p. 63-79, abr. 2009.

LAYRARGUES, P. P. A resolução de problemas ambientais locais deve ser um tema-gerador ou a atividade-fim da educação ambiental. In: REIGOTA, M. (Org.). Verde cotidiano: o meio ambiente em discussão. Rio de Janeiro: DP\&A, 1999.

. Educação para a gestão ambiental: a cidadania no enfrentamento político dos conflitos socioambientais. In: LOUREIRO, C.; LAYRARGUES, P. P.; CASTRO, R. S. (Org.). Sociedade e meio ambiente: a educação ambiental em debate. São Paulo: Cortez, 2000.

A conjuntura da institucionalização da política nacional de educação ambiental. OLAM - Ciência \&t Tecnologia. Rio Claro, v. 2, n. 1, p. 1-14, abr. 2002.

LOUREIRO, C. F. B. (Org.). Educação ambiental no contexto de medidas mitigadoras e compensatórias de impactos ambientais: a perspectiva do licenciamento. Salvador: IMA, 2009a. (Série Educação Ambiental, 5).

. Educação ambiental no licenciamento: aspectos legais e teóricometodológicos. In: (Org.). Educação ambiental no contexto de medidas mitigadoras e compensatórias de impactos ambientais: a perspectiva do licenciamento. Salvador: IMA, 2009b. (Série Educação Ambiental, 5).

LOUREIRO, C. F. B. (Org.). A questão ambiental no pensamento crítico: natureza, trabalho e educação. Rio de Janeiro: Quartet, 2007.

LOUREIRO, C. F. B. et al. Contribuições da teoria marxista para a educação ambiental crítica. Cadernos do CEDES, Campinas, v. 29, n. 77, p. 81-97, 2009.

LÖWY, M. Ecologia e socialismo. São Paulo: Cortez, 2005.

MACEDO, E. F. Parâmetros curriculares nacionais: a falácia de seus temas transversais. In: MOREIRA, A. F. B. (Org.). Currículo: políticas e práticas. Campinas: Papirus, 1999.

MARX, K. O capital: critica da economia política. São Paulo: Nova Cultural, 1988. 
MÉSZÁROS, I. A teoria da alienação em Marx. São Paulo: Boitempo, 2006.

MOREIRA, A. F. B. "Parâmetros curriculares nacionais": críticas e alternativas. In: SILVA, T. T.; GENTILI, P. (Org.). Escola S.A.: quem ganha e quem perde no mercado educacional do neoliberalismo. Brasília: CNTE, 1999.

NEDER, R. T. Problemas de regulação pública e planejamento governamental envolvidos no debate sobra sustentabilidade. Planejamento e Politicas Públicas, Rio de Janeiro, n. 11, p. 109-142, jul./dez. 1994. Disponível em: <http:// www.ipea.gov.br/pub/ppp/ppp11.html>. Acesso em: 28 set. 2008.

NOARA, C. T. A construção dos valores ambientais: um estudo a partir dos Conselhos Municipais de Meio Ambiente no Médio Vale do Itajai, SC. 2007. 110 f. Dissertação (Mestrado em Desenvolvimento Regional) - Universidade Regional de Blumenau, Blumenau, SC, 2007.

NOARA, C. T.; FLORIT, L. F. 0 estudo dos valores ambientais dos Conselhos de Meio Ambiente no Médio Vale do Itajaí: uma contribuição para o Projeto Piava. Revista de Estudos Ambientais, Blumenau, SC, v. 9, p. 115-135, jan./jun. 2007.

NOVICKI, V. Competências socioambientais: pesquisa, ensino, práxis. Boletim Técnico do SENAC, Rio de Janeiro, v. 33, n. 3, p. 19-31, set./dez. 2007a.

Práxis: problematizando consciência e participação na educação ambiental brasileira. In: LOUREIRO, C. F. A questão ambiental no pensamento crítico: natureza, trabalho e educação. Rio de Janeiro: Quartet, 2007b.

PRZEWORSKI, A. Capitalismo e social-democracia. São Paulo: Cia das Letras, 1989.

QUINTAS, J. S. Educação no processo de gestão ambiental: uma proposta de educação ambiental transformadora e emancipatória. In: LAYRARGUES, P. P. (Coord.). Identidades da educação ambiental brasileira. Brasília, DF: MMA, 2004.

QUINTAS, J. S.; GOMES, P. M.; UEMA, E. E. Pensando e praticando a educação no processo de gestão ambiental: uma concepção pedagógica e metodológica para a prática da educação ambiental no licenciamento. Brasilia, DF: IBAMA, 2005.

REIGOTA, M. A. S. Ciência e sustentabilidade: a contribuição da educação ambiental. Avaliação, Campinas, v. 12, n. 2 p. 219-232, 2007.

SERRÃO, M. A.; WALTER, T.; VICENTE, A. S. Educação ambiental no licenciamento; duas experiências no litoral baiano. In: LOUREIRO, C. F. B. (Org.). Educação ambiental no contexto de medidas mitigadoras e compensatórias de impactos ambientais: a perspectiva do licenciamento. Salvador: IMA, 2009. (Série Educação Ambiental, 5). 
SORRENTINO, M. et al. Educação ambiental como política pública. Educação e Pesquisa, São Paulo, v. 31, n. 2, p. 285-299, 2005.

SOUZA, D. B,; NOVICKI, V. Conselhos municipais de meio ambiente: estado da arte, gestão e educação ambiental. Brasilia, DF: Líber, 2010.

TEASS. Tratado de educação ambiental para sociedades sustentáveis e responsabilidade global. Rio de Janeiro, 1992. Disponivel em: <http:// portal.mec.gov.br/seb/arquivos/pdf/teassrg.pdf>. Acesso em: 26 nov. 2009.

UEMA, E. E. Controle social, saber perito e participação. In: LOUREIRO, C. F. B. (Org.). Educação ambiental no contexto de medidas mitigadoras e compensatórias de impactos ambientais: a perspectiva do licenciamento. Salvador: IMA, 2009. (Série Educação Ambiental, 5).

UNESCO. Década da educação das nações unidas para um desenvolvimento sustentável 2005-2014. Brasília, DF, 2005.

. Educação ambiental: as grandes orientações da Conferência de Tbilisi. Brasilia, DF: IBAMA, 1997.

UNIVERSIDADE FEDERAL RIO GRANDE DO SUL. Faculdade de Educação. Análise do documento "Parâmetros curriculares nacionais". In: SILVA, T. T.; GENTILI, P. (Org.). Escola S. A.: quem ganha e quem perde no mercado educacional do neoliberalismo. Brasilia, DF: CNTE, 1999.

VEIGA, A.; AMORIM, E.; BLANCO, M. Um retrato da presença da educação ambiental no ensino fundamental brasileiro: o percurso de um processo acelerado de expansão. Brasilia: MEC, INEP, 2005.

VELASCO, S. L. Algumas anotações sobre a política nacional de educação ambiental. Revista Eletrônica do Mestrado em Educação Ambiental, Rio Grande, v. 8, p. 12-20, jan./jun. 2002. Disponivel em: <http://www.remea.furg.br>. Acesso em: 19 jan. 2010.

. Perfil da lei de política nacional de educação ambiental. Revista Eletrônica do Mestrado em Educação Ambiental. Rio Grande, v. 2, jan./mar. 2000. Disponivel em: <http://www.remea.furg.br/mea/remea/vol2art3.html>. Acesso em: 19 jan. 2010.

WOOD, E. M. Democracia contra capitalismo: a renovação do materialismo histórico. São Paulo: Boitempo, 2006.

Recebido em: 01/06/2010

Aceito para publicação em: 04/10/2010 